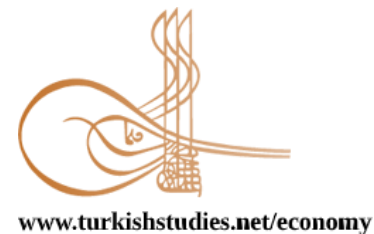

Turkish Studies - Economics, Finance, Politics

eISSN: 2667-5625

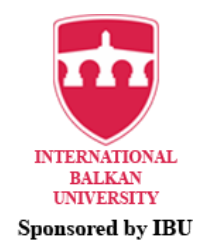

Research Article / Araştırma Makalesi

\title{
Türkiye'de 1969-2020 Yılları Turizm Sektör Performansının Waspas Yöntemiyle Analizi: Covid 19 Etkisi
}

\author{
Analysis of 1969-2020 Years Tourism Sector Performance by Waspas Method in Turkey: \\ The Effect of Covid 19
}

\author{
Hakan Altın*
}

\begin{abstract}
The main objective of the study is an analysis of the performance of the tourism sector in Turkey in the 1969-2020 years. While Turkey has shown the best performance of the tourism sector in the period 2000 years, the lowest performing period is the 1970s. WASPAS method was used in the study. The findings obtained provide the effectiveness of the WASPAS method. Under the ceteris paribus assumption that foreign exchange rates in Turkey are the key factors affecting the tourism sector. In a period when the exchange rates are rising, tourism revenues increase. This situation is also consistent with the findings obtained. In addition, possible effects of COVID 19 on the tourism sector were discussed. In total, the 52year performance of the tourism sector was examined. WASPAS is one of the multi-criteria decision making methods. It can be used in performance ranking. The decision matrix used in the application of the WASPAS method is a 52x6 type matrix consisting of 52 alternatives and 6 criteria. CRITIC and ENTROPY approaches were used as the weighting criteria (significance) of the criteria in the study. Both approaches give close results. The importance of the criteria was calculated as $16.67 \%$ for each criterion.

Performance is the lowest in years when it is in the initial stage of Turkey's outreach efforts for many years. It is a natural result that tourism income and expenditure is low in these years. A result in line with our general expectation has been achieved. The explanation for the period of both crisis and high tourism performance is as follows. Tourism revenues are very sensitive to exchange rates. If there is an increase in exchange rates, there is an increase in tourism revenues due to the competitive prices of export products. In other words, tourism activities will be cheaper with the increase in exchange rates. Demand for goods and services will increase in a market where cheap prices prevail. Therefore, the positive effect of high exchange rate on tourism revenues under the assumption of ceteris paribus is the basis of the best performance years in the 2000s.. This result is also consistent with the result we got from the implementation phase.
\end{abstract}

Structured Abstract: Tourism is considered as one of the most important export items in recent years. It is also seen as both the cause of economic growth and the most important sector benefiting from it. When OECD reports on the effect of COVID-19 are examined, a decrease of $45 \%$ in international tourism is pointed out in 2020. It is stated that if the recovery is delayed until September, this effect will increase up to $70 \%$.

\footnotetext{
* Doç. Dr. Aksaray Üniversitesi, İïF, İşletme Bölümü

Assoc. Prof. Aksaray University, Faculty of Economics and Administrative Sciences, Department of Business

ORCID 0000-0002-0012-0016

hakanaltin@aksaray.edu.tr

Cite as/ Atıf: Altın, H. (2020). Türkiye'de 1969-2020 yılları turizm sektör performansının Waspas Yöntemiyle

analizi: Covid 19 etkisi. Turkish Studies - Economy, 15(3), 1141-1161.
}

https://dx.doi.org/10.47644/TurkishStudies.43413

Received/Geliş: 06 May/Mayıs 2020

Accepted/Kabul: 20 September/Eylül 2020

Copyright $($ INTAC LTD, Turkey

Checked by plagiarism software

Published/Yayın: 25 September/Eylül 2020

CC BY-NC 4.0 
In this study were analyzed by methods WASPAS its performance in the years 1969-2020 the tourism industry in Turkey. In addition, theoretical explanations regarding the possible effects of the COVID 19 pandemic on a global scale are included. The study has two main purposes. First, the analysis of the performance of the tourism sector in the years 1969-2020 in Turkey. The second is the theoretical explanation of the possible impact of COVID 19 on the Tourism Industry.

In total, the 52-year performance of the tourism sector was examined. WASPAS method was used in the study. WASPAS is one of the multi-criteria decision making methods. It can be used in performance ranking. The decision matrix used in the application of the WASPAS method is a 52x6 type matrix consisting of 52 alternatives and 6 criteria. CRITIC and ENTROPY approaches were used as the weighting criteria (significance) of the criteria in the study. Both approaches give close results. The importance of the criteria was calculated as $16.67 \%$ for each criterion. The results obtained from the solution are summarized in Table 1. According to Table 1, the years in which the tourism sector performed best by years were determined as 2001, 2009, 2002, 2003, 2010, 1998, 1997, 2005, 2015 and 2016, respectively. When these years are clustered within themselves, it is seen that 2000s come to the fore. However, the lowest performing years are 1970, 1969, 1972, 1971, 1978, 1979, 1980, 1983, 1981 and 1982 respectively. When these years are clustered within themselves, it is seen that the 1970 s stood out.

It is observed that this year's crisis in Turkey important market in both periods when examined together. In the 1970s, the debt crisis in Turkey has experienced problems of the market and balance of payments. Liberalization of foreign trade has been seen as the most important part of structural adjustment policies for the solution of these problems. During this period, with the decisions of January 24, 1980, the process of opening out and transitioning to a free market economy started. In the 2000s, a new economic stabilization program, which included structural reforms, was introduced in order to reduce chronic high inflation and ensure economic stability. It is the first time that exchange rates have been determined to include inflation. Although a partial improvement has been observed, there has been an excessive increase in import figures after a while there has not been a significant development in exports. Subsequently, the foreign trade deficit reached an unsustainable point. In 2001, after a speculative attack on foreign exchange rates, exchange rates were left to fluctuate (free exchange rate regime). In other words, our national currency has depreciated at high rates and exchange rates have increased very much.

As a result, crises occurred in both periods. Performance is the lowest in years when it is in the initial stage of Turkey's outreach efforts for many years. It is a natural result that tourism revenues and expenditures are low in these years. A result that meets our general expectation has been achieved. The description of the period in which both the crisis was experienced and the tourism performance was high is as follows. Tourism revenues are very sensitive to exchange rates. If there is an increase in exchange rates, tourism revenues increase due to the competitive prices of export products. In other words, tourism activities will be cheaper with the increase in exchange rates. In the market where cheap price is valid, demand for goods and services will increase. Therefore, under the assumption of ceteris paribus, the high exchange rate positively affects tourism revenues under the best performance years in 2000s. This result is also consistent with the result we obtained from the application phase.

The extraordinary developments in communication and transportation with the globalization process after the 1980s made the tourism sector a key sector for the growth and development of countries. Now the expectations of the tourism sector or company are related to the dynamic structure of the market. If the general expectation of the market is positive, the entire sector in the market will be affected positively. If the general expectation of the market is negative, the entire sector will be affected negatively. In some cases, economic developments are so good that this can have a positive impact on the performance of the industry in the field in which it operates. As a result, there are many systematic risks affecting the tourism industry. The other risk is the non-systematic risk and it is entirely the unique risks of the tourism company. All these risks affect the performance of the tourism industry.

The first effect of COVID 19 will be to decrease the tourism cash level, namely tourism revenues. In an environment where revenues are decreasing, tourism companies will either decrease their dividend payments or stop distributing dividends. In both cases, D1 will decrease and estimation P0 will drop. Consequently, the level of cash decreases, profit decreases, and the stock price of the tourism company, the market value, decreases. The second effect is the effect of the growth of tourism companies, that is, to 
investment decisions. Under the influence of COVID 19, growth will decrease or abandon investment. The starting point of the economic recovery for the tourism sector will be the resumption of domestic tourism.

Keywords: Toruism Revenues, Toruism Expenses, Multi-Criteria Decision Making, WASPAS, COVID 19

Öz: Çalışmanın temel amacı Türkiye'de 1969-2020 yıllarında Turizm sektörünün gösterdiği performansın analizidir. Türkiye'de Turizm Sektörünün en iyi performans gösterdiği dönem 2000'li yıllar olurken en düşük performans gösteren dönem 1970'li yıllardır. Çalışmada WASPAS yöntemi kullanılmıştır. Elde edilen bulgular WASPAS yöntemin etkinlik özelliğini sağlamaktadır. Ceteris Paribus varsayımı altında Türkiye'de Turizm Sektörüne etki eden temel faktör döviz kurlarıdır. Döviz kurlarının yükseldiği bir dönemde turizm gelirleri artar. Bu durum elde edilen bulgular ile de tutarlılık göstermektedir. Toplamda Turizm sektörünün 52 yıl performansı incelenmiştir. WASPAS çok kriterli karar verme yöntemlerinden biridir. Performans sıralamasında kullanılabilmektedir. WASPAS yöntemi uygulamasında kullanılan karar matrisi 52 alternatiften ve 6 kriterden oluşan 52x6 tipinde bir matristir. Çalışmada kriterlerin ağırlıklandırma ölçütleri (önem dereceleri) olarak CRITIC ve ENTROPY yaklaşımları kullanılmıştır. Her iki yaklaşım birbirine yakın sonuçlar vermektedir. Kriterlerin önem dereceleri her bir kriter için \%16.67 olarak hesaplanmıştır.

Performansın en düşük olduğu yıllarda Türkiye'nin dışa açılma çabalarının başlangıç aşamasında olduğu yıllardır. Bu yıllarda turizm gelir ve giderinin düşük olması doğal bir sonuçtur. Genel beklentimize uygun bir sonuç elde edilmiştir. Hem kriz yaşandığı hem de turizm performansının yüksek olduğu dönemin açıklaması şu şekildedir. Turizm gelirleri döviz kurlarına karşı çok duyarlıdır. Eğer döviz kurlarında yükselme yaşanırsa ihraç ürünlerinin fiyatlarının rekabetçi olmasından dolayı turizm gelirlerinde artış yaşanır. Başka bir ifadeyle turizm faaliyetleri döviz kurlarının yükselmesiyle ucuzlamıș olacaktır. Ucuz fiyatın geçerli olduğu piyasada mal ve hizmete olan talep yükselecektir. Dolayısıyla 2000'li yıllarda yaşanan en iyi performans yıllarının temelinde ceteris paribus varsayımı altında yüksek döviz kurunun turizm gelirlerine olan olumlu etkisidir. Bu sonuç uygulama aşamasından elde ettiğimiz sonuçla da tutarlıdır.

Anahtar Kelimeler: Turizm Gelirleri, Turizm Giderleri, Çok Kriterli Karar Alma, WASPAS, COVID 19.

\section{Giriş}

Son yıllarda turizm en önemli ihracat kalemlerinden biri olarak kabul edilmektedir. Aynı zamanda hem ekonomik büyümenin nedeni hem de bundan faydalanan en önemli sektör olarak görülmektedir. Büyüyen ekonomik ve sosyal önemi göz önüne alındığında paydaşlar artık sektördeki performansı neyin yönlendirdiğini belirlemekle ilgilenmektedirler. Sektörün hızlı büyümesi destinasyonlar arasında artan çeşitlilik ve rekabete bağlı olarak gelişmektedir. İnternetin hızlı büyümesi ve sunulan turizm ürünleri ve destinasyonlarının çeşitliliği nedeniyle tüketicinin bilgi düzeyini artmıştır.

Turizm faaliyeti aynı zamanda yerel ekonominin çeşitlenmesine de katkıda bulunur ve üzerinde önemli bir çarpan etkisi vardır. Dolayısıyla, hükümetlerin turizm destinasyonlarını sürekli olarak geliştirmeleri yeni destinasyonları keşfederek turizm faaliyetlerini genişletmeleri söz konusudur. Bununla birlikte, turizmin yıkıcı etkileri büyük bir endişe kaynăg 1 haline gelmiştir. Bunu göz önünde bulunduran sürdürülebilir turizm kavramı evrensel olarak turizm gelişiminde arzu edilen ve politik olarak uygun bir yaklaşım kabul edilen turizm faaliyetlerinin olumsuz etkilerini azaltmak amacıyla ortaya çıkmıştır.

Pandemi turizm endüstrisi için daha önce benzeri görülmemiş bir krizdir. COVID-19 etkisine ilişkin OECD raporları incelendiğinde 2020 yılında uluslararası turizmde $\% 45$ düşüşe işaret edilmektedir. Eğer iyileşme Eylül ayına kadar ertelenirse bu etki \% 70'e kadar yükseleceği ifade edilmektedir. Sektör GSYİH'nın ortalama \% 4,4'üne ve OECD ülkelerinde istihdamın ortalama \% 6,9'una doğrudan katkıda bulunmaktadır.

Çalışmada Türkiye'de Turizm Sektörünün 1969-2020 y1llarında gösterdiği performans WASPAS yöntemiyle analiz edilmiştir. Elde edilen bulgular kullanılan yöntemin etkinlik özelliğini 
sağlamaktadır. Ayrıca, küresel ölçekte yaşanan COVID 19 pandemisinin olası etkilerine yönelik kuramsal açıklamalara yer verilmiştir.

\section{Literatür}

Literatür iki bölümden oluşmaktadır. Birincisi, turizm sektörünün performansına ilişkin çalışmalardır. Bu ilişkinin daha çok kalitatif yönleriyle ele alındığı görülmektedir. İkincisi, COVID 19 Pandemesinin turizm sektörüne olan etkisidir. Çalışmalardan elde edilen sonuçlar şu şekildedir:

Augustyn ve Knowles, (2000) çalışmasında turizm destinasyonlarında kamu ve özel sektör arasındaki ortaklıklar için kritik başarı faktörlerini belirlemeyi ve bu düzenlemelerin performansını değerlendirmiştir. Turizm ortaklıkları için kritik başarı faktörleri belirlenmiştir. Bunlar arasında uzmanlık gerektiren hazırlık, temel hedeflerin belirlenmesi, gelişmeye açık esnek bir yapı, etkin eylemler ve ortaklıkların sürdürülebilir doğası bulunmaktadır. Sağlam nedenlere dayanan bu tür ortaklık girişimleri kamu ya da özel sektör tarafından yürütülmektedir. Kaynaklar çeşitli kamu ve özel kaynaklardan elde edilir. Ortaklardan hem doğrudan (mali) hem de dolaylı (ayni yardım) destek içerir. Kamu ve özel sektör arasındaki ortaklıklar son zamanlarda turizm gelişimi için stratejik bir araç olarak öne çıkmıştır.

(Croes 2005) çalışmasında küreselleşme koşulu altında turizm performansını ölçmenin en etkili biçiminin ne olduğunu araştırmıştır. Bunun için iki yaklaşım sunmuş ve analiz etmiştir. Birincisi, uluslararası turizm geliş ve gelirlerinin yıllık ortalama büyüme oranlarına dayanan geleneksel yaklaşımdır. $\mathrm{Bu}$ yaklaşımda performansın değerlendirilmesi sırasında kullanılan destinasyon noktasındaki oynaklık, yaratılan hizmetin değerini ve tedarik kısıtlamaları gibi yapısal gerçeklerin stratejik politika oluşturmayı engellediği ve iş kararlarının kalitesinin bozabileceğidir. Buna karşın, ikinci yaklaşım değer geliştirme kavramına dayalı alternatif yaklaşımdır. Değer yaklaşımı, döviz üretiminin etkililiği kavramına dayanır ve talebe bağlıdır. Bu alternatif model, turistlerin uluslararası varışlar, kesilen faturaları, enflasyon ile değerin artırması veya azalması gibi piyasada bulunan yapısal koşulları daha doğru bir şekilde yansıtır.

(Phillips ve Louvieris, 2005) çalışmasında turizm, konaklama ve eğlence amaçlı küçük orta ölçekli işletmelerin performansını artırma arzularına yönelik olarak performans ölçüm süreçlerini analiz etmiştir. Sonuçlar, dört temel kavramın ölçüm ve performansı etkilediğini ortaya koymuştur. Bunlar, toplam geliri artırmak amacıyla bütçe kontrolünün kullanılması, müşteri ilişkileri yönetimi, iç iş süreçlerinin gerekliliği ve öğrenmeyi teşvik etmektir.

(Yılmaz ve Bititci, 2006) çalışmasında değer zinciri kavramının turizm sektöründe süreçleri yönetmek ve ölçmek için kullanılabilirliğini göstermeye çalışmıştır. Çalışmada önerilen model, turizm endüstrisini bir değer zinciri olarak inceleme ve çeşitli oyuncuların süreçlerini ve faaliyetlerini iletişim ve koordine etmesini sağlayacak bir değer zinciri odaklı performans yönetimi ve ölçüm çerçevesi geliştirme firsatı yaratmaktadır. Bu nedenle, turizm ürün ve hizmetlerinin genel verimliliğini ve etkinliğini bir değer zinciri yönetimi perspektifinden ölçmek ve yönetmek kritik hale gelmektedir. Bu yaklaşımın özellikle dikey veya yatay olarak entegre edilmiş olsun olmasın turizm şirketleri için müşteri ilişkilerinin etkililiğini ve iç verimliliğini ölçmek açısından faydalı olabileceğini ileri sürmektedirler.

(Chen, 2010) çalışmasında ekonomi ve turizm büyümesinin otellerinin kurumsal performansı üzerindeki etkisini araştırmaktadır. Söz konusu kurumsal performans göstergeleri doluluk oranı (OPR), aktif getirisi (ROA), özkaynak getirisi (ROE), hisse senedi getirisi, kısa ve uzun vadeli ödeme gücüdür. Ekonominin genel durumundaki değişimlerin (reel GSYİH büyüme oranı, DGDP) ve turizm büyümesinin (toplam yabanc1 turist varışlarının büyüme oranı, DTA) turizm otellerinin kurumsal performansı üzerindeki etkileri incelenmiştir. Hem DGDP hem de DTA OPR'nin önemli açıklayıcı faktörleridir. Ayrıca, DTA, ROA ve ROE güçlü bir şekilde etkilemektedir. Ancak ne DGDP ne de DTA'nın pay senedi performansı üzerinde önemli bir etkisi 
yoktur. Otel endüstrisindeki genel finansal performansın tanımlanmasında ekonomik faktör DGDP, endüstri faktörü DTA'dan biraz daha önemli olduğunu ileri sürmüştür.

(Inoue ve Lee, 2011) çalışmasında kurumsal sosyal sorumluluğun (CSR) belirli boyutları ile kurumsal finansal performans (CFP) arasındaki ilişkiyi araştırmıştır. CSR'nin beş boyutu vardır. Bunlar, çalışan ilişkileri, ürün kalitesi, topluluk ilişkileri, çevre sorunları ve çeşitlilik sorunlarıdır. Her bir boyutun turizmle ilgili ancak farklı sektörde faaliyet gösteren dört şirketin finansal performansını nasıl etkileyeceğini incelemiştir. Tüm CSR boyutlarının olumlu finansal etkilere sahip olduğu ileri sürülürken, sonuçlar her bir boyutun kısa vadeli ve gelecekteki kârlılık üzerinde farklı bir etkiye sahip olduğunu ve bu tür finansal etkilerin dört sektörde değiştiğini ortaya koymaktadır. Bulgular, turizm yöneticilerine CSR faaliyetlerinin boyutlarının şirketlerinin finansal performansını artıracağı konusunda bilgi vermektedir.

(Barros, vd., 2011) çalışmasında turizm bölgelerinin performans değerlendirmesini yapmıştır. Bulgular, çeşitli bölgelerde birkaç verimlilik faktörünün olduğunu göstermiştir. Bunlar arasında en önemlileri, deniz, güneş ve plaj donanımına dayalı stratejilerdir. Belirli bir bölgedeki tema parkları, anıtlar, müzeler, kayak merkezleri ve tabiat parklarının geliştirilmesi, bu cazibe merkezlerinin turistlerin kalış süresini uzatabildiği böylece de verimliliği artırabileceğini ileri sürmektedirler. Turizm kaynaklarının kullanımındaki teknik verimliliğin yani performansın neden hedef rekabetçiliğinin bir temsilcisi olarak değerlendirilebileceğini açıklamışlardır.

(Chen, 2011) çalışmasında uluslararası turizm gelişimi ve krizlerin otel performanslarına olan etkisini incelemiştir. Otel performans ölçümleri gelir (mevcut oda başına gelir ve doluluk oranı), kârlılık (varlık getirisi ve özkaynak getirisi) ve pay senedi performansıdır. Test sonuçları ilk olarak, toplam gelen turist gelişlerinin büyümesiyle temsil edilen uluslararası turizm gelişiminin (ITD), otel satışları, kârlılık üzerinde ve pay senedi performansı üzerinde etkili olduğunu göstermektedir. İkincisi, yatırımcıların gelecekteki nakit akışlarının değişen zamana bağlı olarak değişme gösteren iskonto oranından kaynaklandığını tespit edilmesidir. Üçüncüsü, depreminin ve terörist saldırılarının neden olduğu olumsuz durumun pay senetlerinin düşük performans göstermesine neden olmasıdır. Son olarak, ITD'nin otel pay senedi performansı üzerindeki etkisi genişleme dönemlerinde hala önemsiz olmakla birlikte, ITD daralma dönemlerinde pay senedi getirilerini önemli ölçüde düşürmektedir.

(Assaf ve Josiassen, 2012) çalışmasında turizm endüstrisinin kilit faktörleri ve endüstri performansına katkıda bulunan belirleyiciler üzerine bir çalışma yapmıştır. Uluslararası turizm endüstrisi artan sayıda varlıklı tüketici tarafından yönlendirilen uzun bir büyüme döneminden sonra şu anda daha zayıf bir dünya ekonomisinin etkilerine maruz kalmaktadır. Bu durum daha zorlu piyasa koşulları ve artan rekabete yol açmıştır. Ülkeler, turizm endüstrileri ve turizm işletmeleri, kendilerini uluslararası turistlere şiddetle tanıtarak, maliyetleri düşürerek ve turizm çabalarında sinerjileri belirleyerek turizm endüstrisinin ve bileşenlerinin performansını iyileştirmeye çalışırlar. Performansı artırmanın önündeki en önemli engel turizm performansını etkileyebilecek çok sayıda belirleyicinin varlığıdır.

(Hashemkhani Zolfani, vd., 2015) çalışmasında sürdürülebilir turizm tanımları ve uygulamaları hakkındaki literatürün kapsamlı bir incelemesini sunmaktadır. Turizm hem çevreyi etkileyen hem de çevreden etkilenen önemli bir küresel sistemdir. Bu itibarla, turizm, sistemin tüm yönlerinde çevre korumanın zorluklarına değinmelidir. $\mathrm{Bu}$ durum turizm sisteminin karmaşıklı̆̆ının ve bileşenlerinin birbiriyle ilişkili doğasının anlaşılmasına dayanan çevre sorunlarına sistem çapında bir yaklaşım gerektirir. Sosyal, ekonomik ve çevresel boyutlar çok kapsamlıdır ve turizmde sürdürülebilirliğin çok boyutlu olduğu görülmektedir. Sürdürülebilirliğin ve sürdürülebilir kalkınmanın özünde dinamik olması yatar. Gelişmeler dinamik sürdürülebilirlik çerçevesinin farklı yönleri ve perspektifleri içinde düşünülmelidir. Turizmde bu yeni perspektifin kavramı ve uygulaması sadece sağl1klı ve sürdürülebilir bir turizm endüstrisine sahip olmakla 
kalmayıp aynı zamanda ülkelerin ve şimdiki ve gelecekteki paydaşlarının ekonomik büyümesinde önemli bir rol oynayacaktır.

(Rodríguez ve Espino, 2016) çalışmasında turizm destinasyonunda sürdürülebilirlik faktörlerini ve performansı belirlemek için paydaşların görüşlerine dayanan bir metodoloji geliştirilmiştir. Bir turizm destinasyonunun rekabet gücü, ekonomik ve çevresel kaynaklarının sürdürülebilirliğine bağlıdır. Araştırmada kullanılan değişkenler, çevre kaynakları, turizm tedarik zincirindeki başlıca etmenler, destinasyonun yönetişimi ve turizm destinasyonunun rekabet gücünü artıran tamamlayıcı özelliklerdir. Performans hedefin sürdürülebilirliğini etkileyecek ana değişkenleri oluşturmak için paydaşlar tarafından; hedef ve müşteriler olmak üzere iki açıdan ölçülmektedir. Sonuçlar, performansla doğrudan ve anlamlı bir ilişkisi olan kilit faktörlerin tedarik zinciri, güvenlik, serbest zaman ve yönetişim olduğunu göstermiştir.

(Boley, vd., 2017) çalışmasında turizm araştırmalarında kullanılan en yaygın metodolojik araçlardan biri olan önemli performans analizi (IPA) ile destinasyon sakinlerinin sürdürülebilir turizm girişimleri hakkındaki algılarını incelemiştir. Stratejik planları dahilinde sürdürülebilir turizme vurgulanan çeşitli seviyelerde yerleşik tutumların IPA'sını gerçekleştirmişlerdir. Sonuçlar, sakinlerinin IPA'lara eşit derecede yüksek önem verdiklerini ancak performans algılarında farklılık gösterdiğini ortaya koymaktadır. Stratejik planların içinde sürdürülebilir turizme en fazla önem verilen bölgenin en yüksek performans değerlendirmesine sahip olduğu tespit edilmiştir. Bu bilgiler, bölgenin çevresel kalitesini sürdürmesini ve korumasını açısından son derece önemlidir. Ayrıca, yerli halkın sosyal ve rekreasyonel alanların turizm için önemi olduğunu ve bu yerlerin bozmamasını gerektiğini anlamaları sağlamış olacaktır.

(Theodoulidis, vd., 2017) çalışmasında turizm endüstrilerinde kurumsal sosyal sorumluluk (CSR) ile kurumsal finansal performans (CFP) arasındaki ilişkiyi incelemiştir. Stratejik paydaş modeli ve iç paydaş bağlılık modellerini kullanmışlardır. Sonuçlar CSR faaliyetleri olarak ifade edilen paydaş yönetimi uygulamalarının, incelenen dört endüstrinin her biri için firma stratejisi ve CFP ile etkileşimi hakkında yararlı bilgiler sunmaktadır. Bu nedenle, turizmle ilgili endüstrilerin yöneticileri ve turizmle ilgili diğer paydaşların, firmaların sosyal ve çevresel faaliyetlerinin rolü üzerinde çalışanlarının, sundukları ürünlerin, kamu algılarının, uyguladıkları çeşitlilik stratejisinin ve çevre ile ilgili faaliyetlerin nasıl piyasa değeri yarattı̆ının farkında olmaları gerekir.

(Gössling, vd., 2020) çalışmasında COVID 19'un turizm sektörüne olan etkisini araştırmışlardır. Aşının olmaması ve hastalığı tedavi etmek için sınırlı tıbbi kapasitesi ile farmasötik olmayan müdahaleler pandemiyi kontrol altına almak için ana stratejidir. Eşi görülmemiş küresel seyahat kısıtlamaları ve evde kalma kısıtlamaları İkinci Dünya Savaşı'ndan bu yana küresel ekonominin en ciddi bozulmalarına neden olmaktadır. Dünya nüfusunun\% 90'ından fazlasını etkileyen uluslararası seyahat yasakları ve halka açık toplantılar ve topluluk hareketliliği üzerindeki yaygın kısıtlamalar nedeniyle turizm sektörü Mart 2020'de büyük ölçüde olumsuz etkilenmiştir. Hava yolculuğu, yolculuklar ve konaklama üzerindeki etkilere ilişkin erken kanıtlar nu etkinin yıkıcı olduğunu göstermektedir.

(Qiu, vd., 2020) çalışmasında COVID-19 salgını sırasında turizmin sosyal maliyetleri konusunu incelemişlerdir. Tüm dikkatler turist destinasyonlarındaki halka (çalışanlarına) çevrilmiştir. Onların güvenlik ve refahları ile turizm faaliyetinin durması nedeniyle katlanacakları maliyetlerin önemli olduğuna dikkat çekmişlerdir. Sosyal maliyetler nedeniyle önemli derecede olumsuz sosyo-ekonomik etkilere maruz kalan turistik destinasyonlarda, topluma fayda sağlamak için yardım paketleri tasarlanmalıdır. Konvansiyonel politika önlemleri, insanların turizmle ilgili halk sağlığı risklerine ilişkin algısını derinden değiştirdiği için bu krizin üstesinden gelemeyebilir.

(Farzanegan, vd., 2020) çalışmasında uluslararası turizm ile COVID-19 vakaları ve buna bağlı ölümler arasındaki ilişkiyi incelemişlerdir. Uluslararası turizm ile kümülatif COVID-19 vaka düzeyi ve ölüm arasında pozitif bir korelasyon vardır. Sonuçlar, yüksek uluslararası turizm akışına 
maruz kalan ülkelerin COVID-19 salgınının neden olduğu vakalara ve ölümlere daha yakın olduğunu göstermektedir. Bu ilişki, COVID-19 salgınının diğer sosyo ekonomik belirleyicileri için de tutarlidir.

(Higgins-Desbiolles, 2020) çalışmasında COVID 19'un turizmin sektöründe yaşanması muhtemel dönüşümünü eleştirel bir bakış açısıyla incelemiştir. 2019-2020'deki COVID-19 salgını, turizm endüstrisini ve faaliyet gösterdiği bağlamı dönüștürme potansiyeline sahiptir. Dünyanın birçok yerinde seyahat, turizm, misafirperverlik ve etkinliklerin durdurulduğu bu küresel kriz, bu tarihi dönüştürücü gerçek dünyada olasılıkları ortaya çıkarmak için bir firsat sunmaktadır. COVID19 salgın krizi, turizmi gelecek için daha iyi bir yola doğru yeniden ulaştırmak ve turizm ile ilgili tüm bilinenleri sıfırlamak için bir alan yaratabilir.

(Renaud, 2020) çalışmasında COVID-19 ve kitle kruvaziyer turizmin ilişkisini eleştirel bir bakış açısıyla incelemiştir. COVID-19'un bir sonucu olarak kruvaziyer turizmi durdurmuştur. Ancak 2021'de yeniden başlaması muhtemel olduğundan bu turizm biçiminin ilgi düzeyini yeniden sorgulamış ve sektörün küreselleşme ve küçülme ile uyumlu gelecekteki kalkınma alternatifleri önermiştir. "Kalkınma için Büyüme" den "Yaşanabilirlik için Küçülme" ye geçişin desteklemesi gibi radikal çözüm önerileri vardır.

\section{3. Çalışmanın Amacı ve Kapsamı}

Çalışmanın iki temel amacı vardır. Birincisi, Türkiye'de 1969-2020 yıllarında Turizm Sektörünün performansının analizidir. İkincisi, COVID 19'un Turizm Sektörüne olası etkisinin kuramsal açıklanmasıdır. Çalışmada kullanılan veriler Türkiye Seyahat Acenteleri Birliği (TURSAB) web sayfasından alınmıştır. 2020 yılı verileri kesinleşmemiş rakamlardan oluşmaktadır. Toplamda Turizm sektörünün 52 y1l performansı incelenmiştir. Çalışmada WASPAS yöntemi kullanılmıştır. WASPAS çok kriterli karar verme yöntemlerinden biridir. Performans sıralamasında kullanılabilmektedir.

WASPAS yöntemi uygulamasında kullanılan karar matrisi 52 alternatiften ve 6 kriterden oluşan 52x6 tipinde bir matristir. Amaç fonksiyonunda kriterler C1; İhracat Rakamları (Log.), C2; Turizm Gelirleri (Log), C3; Turizm Gelirlerinin İhracata Oran1, C4; İthalat Giderleri (Log), C5; Turizm Giderleri (Log), C6; Turizm Giderlerinin İthalata Oranı olarak oluşturulmuştur. Çalışmada kriterlerin ağırlıklandırma ölçütleri (önem dereceleri) olarak CRITIC ve ENTROPY yaklaşımları kullanılmıştır. Her iki yaklaşım birbirine yakın sonuçlar vermektedir. Kriterlerin önem dereceleri her bir kriter için \%16.67 olarak hesaplanmıştır.

\section{4. Çalışmada Kullanılan Yöntem}

\subsection{Waspas Yöntemi}

Modelin matematiksel formu için (Chakraborty, vd., 2015, s.3-5 ve Zavadskas, vd., 2015, s.78-79) çalışmalarından yararlanılmıştır.

WASPAS yöntemi, iki iyi bilinen çok kriterli karar verme yöntemlerinden Ağırlıklı Toplam Modeli (WSM) ve Ağırlıklı Ürün Modelinin(WPM) bir kombinasyonudur. Uygulaması önce bir karar (değerlendirme) matrisinin geliştirilmesiyle başlar.

$$
X=\left[x_{i j}\right]_{m \times n}
$$

Burada, xij, j. ölçütüne göre i. inci alternatifinin performansıdır. M, alternatiflerin sayısını, n, kriterlerin sayısını göstermektedir. Performans ölçümlerini karşılaştırılabilir ve boyutsuz hale getirmek için, karar matrisindeki tüm unsurlar aşağıdaki iki denklem kullanılarak normalleştirilir:

$$
\bar{x}_{i j}=\frac{x_{i j}}{\max _{i} x_{i j}} \text { faydalı kriterleriçin }
$$


$\bar{x}_{i j}=\frac{\min _{i} x_{i j}}{x_{i j}}$ faydalı olmayan kriterler için

Burada, çizgi xij , xij'in normalleştirilmiş değeridir.

WASPAS yönteminde, iki optimallik kriterine dayanarak ortak bir iyimserlik kriteri aranmaktadır. Optimallerin ilk kriteri, yani ortalama ağırlıklı bir başarı kriteri WSM yöntemine benzemektedir. Bir dizi karar kriterine göre bir dizi alternatifi değerlendirmek için uygulanan çok kriterli karar verme (MCDM) yaklaşımıdır. WSM yöntemine göre, alternatifin toplam nispi önemi aşağıdaki gibi hesaplanır:

Burada, çizgi xij, xij'in normalleştirilmiş değeridir.

WASPAS yönteminde, iki optimallik kriterine dayanarak ortak bir iyimserlik kriteri aranmaktadır. Optimallerin ilk kriteri, yani ortalama ağırlıklı bir başarı kriteri WSM yöntemine benzemektedir. Bir dizi karar kriterine göre bir dizi alternatifi değerlendirmek için uygulanan çok kriterli karar verme (MCDM) yaklaşımıdır. WSM yöntemine göre, alternatifin toplam nispi önemi aşağıdaki gibi hesaplanır:

$$
Q_{i}^{(1)}=\sum_{j=1}^{n} \bar{x}_{i j} w_{j}
$$

wj, jth ölçütünün (göreceli önem) ağırlığıdır.

Öte yandan, WPM yöntemine göre alternatifin toplam nispi önemi aşağıdaki denklem kullanılarak hesaplanır:

$$
\left.Q_{i}^{(2)}=\prod_{j=1}^{n} \overline{\left(x_{i j}\right.}\right)^{w j}
$$

Daha sonra, katk1 ve çarpma yöntemlerinin ağırlıklı kümelenmesinin ortak genel bir kriteri için aşağıdaki denklem önerilmektedir.

$$
Q_{i}=0,5 Q_{i}^{(1)}+0,5 Q_{i}^{(2)}=0,5 \sum_{j=1}^{n} \bar{x}_{i j} w_{j}+0,5 \prod_{j=1}^{n} \overline{\left(x_{i j}\right)^{w j}}
$$

Karar verme sürecinin sıralama doğruluğunu ve etkinliğini arttırmak için WASPAS yönteminde, alternatifin toplam göreceli önemini belirlemek için daha genel bir denklem aşağıdaki gibi verilir.

$$
\left.Q_{i}=\lambda Q_{i}^{(1)}+(1-\lambda) Q_{i}^{(2)}=\lambda \sum_{j=1}^{n} \bar{x}_{i j} w_{j}+(1-\lambda) \prod_{j=1}^{n} \overline{\left(x_{i j}\right.}\right)^{w j}, \lambda=0,0.1, \ldots, 1
$$

Uygulanabilir alternatifler artık Q değerlerine göre sıralanmıştır ve en iyi alternatif en yüksek Q değerine sahiptir. Denklem (6), $\lambda$ değeri 0 olduğunda, WASPAS yöntemi WPM'ye dönüşürken ve $\lambda 1$ olduğunda, WSM yöntemi olur. Sıralama doğruluğunu artırmak için MCDM problemlerini çözmek için uygulanmıştır ve en yüksek tahmin doğruluğuna ulaşma kabiliyetine sahiptir.

Belirli bir karar verme problemi için, en uç fonksiyon aranırken $\lambda$ 'nın optimal değerleri belirlenmesi için aşağıdaki formül kullanılır.

$$
\lambda=\frac{\sigma^{2}\left(Q_{i}^{(2)}\right)}{\sigma^{2}\left(Q_{i}^{(1)}\right)+\sigma^{2}\left(Q_{i}^{(2)}\right)}
$$

Turkish Studies - Economy, 15(3) 
Varyanslar aşağıdaki denklemler uygulanarak hesaplanabilir:

$$
\begin{aligned}
& \sigma^{2}\left(Q_{i}^{(1)}\right)=\sum_{j=1}^{n} w_{j}^{2} \sigma^{2}\left(\overline{x_{i j}}\right) \\
& \sigma^{2}\left(Q_{i}^{(2)}\right)=\sum_{j=1}^{n}\left[\frac{\prod_{j=1}^{n} \overline{\left(x_{i j}\right)^{w j}} w_{j}}{\left.\left.\overline{\left(x_{i j}\right.}\right)^{w j} \overline{\left(x_{i j}\right.}\right)^{(1-w j)}}\right] \sigma^{2}\left(\overline{x_{i j}}\right)
\end{aligned}
$$

Normalize edilmiş ilk kriter değerlerinin varyans tahminleri aşağıdaki gibi hesaplanır

$$
\sigma^{2}\left(\overline{x_{i j}}\right)=\left(0.05 \bar{x}_{i j}\right)^{2}
$$

WASPAS yöntemindeki alternatif tahminlerin varyansları, WSM ve WPM yaklaşımlarının varyasyonlarına ve $\lambda$ değerine bağlıdır. En uygun $\lambda$ değerlerini hesaplamak ve maksimum tahmin doğruluğunu sağlamak faydalıdır. Optimal $\lambda$ değerlerinin alternatiflerin son sıralaması üzerindeki etkilerini incelemek de önemlidir.

\section{2. Çözüm}

İlk aşamasında karar matrisi oluşturulur. Karar matrisi Ek- 1'de gösterilmiştir. Karar matrisi 52 alternatif ve 6 karar kriterinden oluşan 52x6 tipinde bir matristir. Amaç fonksiyonunda karar kriterler C1; C2; C3; C4; C5; ve C6 olarak gösterilmiştir. Tablonun en alt satırında her bir karar kriterin amaç fonksiyonundaki tanımına uygun olarak maksimum ve minimum değerleri belirlenmiştir. İkinci aşamada, normalize edilmiş karar matrisi çizgi (Xij) elde edilmiştir. Hesaplanan değerler Ek- 2'de gösterilmiştir. Bunun için (1) ve (2) nolu denklemler kullanılarak her bir gözlem değeri (Xij), amaç fonksiyona uygun olarak maksimum ve minumum değerlerlere bölünmüş̧ür. Üçüncü aşamada, ortalama ağıllıklı bir başarı kriteri WSM hesaplanmıştır. Hesaplanan değerler Ek- 3'te gösterilmiştir. Bunun için normalize edilmiş karar matrisindeki her bir gözlem değeri çizgi (Xij), ağırlık kriterleri ile çarpılarak satır toplamları alınmıştır. Bunun için (3) numaralı denklem kullanılmıştır. Dördüncü aşamada, WPM yöntemine göre alternatifin toplam nispi önemi hesaplanmıştır. Hesaplanan değerler Ek- 4'te gösterilmiştir. Bunun için Ek- 3'te hesaplanış her gözlemin çizgi (Xij), ağırlık kriteri derecesinde önce kuvveti daha sonra satır çarpımları alınmıştır. Bunun için (4) numaralı denklem kullanılmıştır. Beşinci aşamada, katkı ve çarpma yöntemlerinin ağırlıklı kümelenmesinin ortak genel bir kriteri hesaplanmıştır. Hesaplanan değerler Ek- 5'te gösterilmiştir. Bunun için Q1 ve Q2 toplamları 0,5 sabiti ile çarpılmıştır. Bunun için (5) numaralı denklem kullanılmıştır. Elde edilen Q değerleri başarı sıralamasında kullanılacak değerleri göstermektedir. Altıncı aşamada, alternatifin toplam göreceli önemini belirlemek için daha genel bir denklem kullanılabilir. Bu denklem (6) numaralı denklemdir. Ancak, kullanılan karar matrisindeki alternatiflerin zaman serisi verilerinden oluşması bu denklemin kullanılmasını gereksiz kılmıştır. Bu yüzden bir hesaplama yapılmamıştır. Bunun yerine ağırlıklandırılmış ortak genel kriter değerleri ve sıralama değerleri Ek- 6'da gösterilmiştir. Son aşamada, optimal lamda değeri hesaplanarak elde edilen bulguların etkinliği sınanmıştır. Hesaplanan değerler Ek- 7'de gösterilmiştir. Bunun için denklem (7) kullanılmıştır. Yıllar itibarıyla optimal lambda değerinin tüm yıllar için ideal değer 0,5 'e yakın olduğu bulunmuştur.

Çözümden elde edilen sonuçlar Tablo 1 de özetlenmiştir. Tablo 1 incelenen dönem boyunca turizm sektörünün performans1 en iyi 10 yıl ile performans1 en düşük 10 yıl olmak üzere iki bölümden oluşmaktadır. Tablo 1'e göre turizm sektörünün yıllar itibarıyla en iyi performans gösterdiği yıllar sirasıyla 2001, 2009, 2002, 2003, 2010, 1998, 1997, 2005, 2015 ve 2016 yılları 
olarak tespit edilmiştir. Bu yıllar kendi içerisinde kümelendiğinde 2000'li yılların öne çıktığı görülür. Buna karşın en düşük performans gösteren y1llar sırasıyla 1970, 1969, 1972, 1971, 1978, 1979, 1980, 1983, 1981 ve 1982 yıllarıdır. Bu yıllar kendi içerisinde kümelendiğinde 1970'li yılların öne çıktığı görülür.

Tablo 1: Turizm Sektöründe Seçilmiş Yıllar

\begin{tabular}{|c|c|c|}
\hline Yıllar & Q Değeri & Sıralama \\
\hline 2001 & 1,5408 & 1 \\
\hline 2009 & 1,5298 & 2 \\
\hline 2002 & 1,5051 & 3 \\
\hline 2003 & 1,4816 & 4 \\
\hline 2010 & 1,4755 & 5 \\
\hline 1998 & 1,4694 & 6 \\
\hline 1997 & 1,4522 & 7 \\
\hline 2005 & 1,4465 & 8 \\
\hline 2015 & 1,4449 & 9 \\
\hline 2016 & 1,4449 & 10 \\
\hline 1970 & 1,0233 & 43 \\
\hline 1969 & 1,004 & 44 \\
\hline 1972 & 0,9895 & 45 \\
\hline 1971 & 0,9108 & 46 \\
\hline 1978 & 0,8976 & 47 \\
\hline 1979 & 0,8834 & 48 \\
\hline 1980 & 0,8485 & 49 \\
\hline 1983 & 0,8224 & 50 \\
\hline 1981 & 0,7931 & 51 \\
\hline 1982 & 0,7884 & 52 \\
\hline
\end{tabular}

\section{Seçilmiş Yıllarda Turizm Sektörü Analizi}

En iyi performans ve en düşük performans yılları birlikte incelendiğinde her iki dönemde Türkiye piyasalarında önemli krizlerin yaşandığı görülmektedir. Türkiye piyasalarında 1970'li yıllarda borç krizi ve ödemeler dengesi sorunları yaşanmıştır. Bu sorunların çözümü için yapısal uyum politikalarının en önemli parçası olarak dış ticaretin serbestleşmesi görülmüştür. Bu sürede 24 Ocak 1980 kararları ile birlikte dışa açılma ve serbest piyasa ekonomisine geçiş sürecine başlanmıştır. 2000'li yıllarda kronik yüksek enflasyonun düşürülmesi ve ekonomik istikrarın sağlanması amacıyla yapısal reformları içerine yer alan yeni bir ekonomik istikrar programı uygulanmaya başlamıştır. İlk defa döviz kurları enflasyonu da içerisine alacak şekilde belirlenmeye başlanmıştır. Kısmı bir iyileşme görülse de bir süre sonra ithalat rakamlarında aşırı artış yaşanırken ihracatta önemli bir gelişme yaşanmamıştır. Devamında dış ticaret açı̆̆ı sürdürülemez bir noktaya gelmiştir. 2001 yılında döviz kurlarına yönelik spekülatif bir atak sonrasında döviz kurları dalgalanmaya (serbest kur rejimi) bırakılmıştır. Başka bir ifadeyle ulusal paramız yüksek oranlarda değer kaybederek döviz kurları çok yükselmiştir. Sonuç olarak yeni bir kriz yaşanmıştır. 
Sonuç olarak her iki dönemde krizler yaşanmıştır. Performansın en düşük olduğu yıllarda Türkiye'nin dışa açılma çabalarının başlangıç aşamasında olduğu yıllardır. Bu yıllarda turizm gelir ve giderinin düşük olması doğal bir sonuçtur. Genel beklentimize uygun bir sonuç elde edilmiştir.

Hem kriz yaşandığı hem de turizm performansının yüksek olduğu dönemin açıklaması şu şekildedir. Turizm gelirleri döviz kurlarına karşı çok duyarlıdır. Eğer döviz kurlarında yükselme yaşanırsa ihraç ürünlerinin fiyatlarının rekabetçi olmasından dolayı turizm gelirlerinde artış yaşanır. Başka bir ifadeyle turizm faaliyetleri döviz kurlarının yükselmesiyle ucuzlamış olacaktır. Ucuz fiyatın geçerli olduğu piyasada mal ve hizmete olan talep yükselecektir. Dolayısıyla 2000'li yıllarda yaşanan en iyi performans yıllarının temelinde ceteris paribus varsayımı altında yüksek döviz kurunun turizm gelirlerine olan olumlu etkisidir. Bu sonuç uygulama aşamasından elde ettiğimiz sonuçla da tutarlıdır.

1980'li y1llardan sonra küreselleşme süreciyle iletişim ve ulaştırmada yaşanan olağan üstü gelişmeler turizm sektörünü ülkelerin büyümesi ve kalkınması yönünde kilit bir sektör haline getirmiştir. Artık turizm sektörün veya şirketinin beklentisi piyasanın dinamik yapısıyla ilgilidir. Eğer piyasanın genel beklentisi olumlu yöndeyse piyasadaki tüm sektör bundan olumlu etkilenirler. Eğer piyasanın genel beklentisi olumsuz yöndeyse tüm sektör bundan olumsuz etkilenir. Bazı durumlarda ekonomik gelişmeler o kadar iyidir ki bu durum sektörün kendi faaliyet gösterdiği alandaki performansının üzerinde olumlu bir etki yaratabilir. Sonuç olarak turizm sektörünü etkileyen çok sayıda sistematik risk vardır. Diğer risk ise sistematik olmayan risktir ve tamamıyla turizm şirketinin kendine özgü riskleridir. Tüm bu riskler turizm sektörünün performansını etkiler.

\section{Covid 19'un Turizm Sektörüne Olası Kuramsal Etkisi}

Covid 19'un Turizm sektörüne olan etkisi Gordon Modeli ve İskonto Edilmiş Kâr Pay1 yaklaşımlarıyla açıklanabilir. $\mathrm{Bu}$ yaklaşımların matematiksel formu aşağıdaki gibidir. Gordon Modelinde kullanılan bileşenler şapka $\mathrm{P}_{0}$ tahmin edilen pay senedi fiyatını, $\mathrm{D}_{1}$ bir sonraki dönem ödenecek temettü tutarını, şapka rs beklenen getiri tutarını, g şirketin büyüme değerini göstermektedir. Bu ilişki (11) ve (11a) formülleri ile gösterilmiştir. (11a) formülünün ilk bileşeni yatırımcının pay senedi yatırımından beklediği ilk kazanç temettü veya temettü verimini, ikinci bileşen sermaye kazancını veya sermaye verimliliğini göstermektedir.

$$
\begin{aligned}
& {\stackrel{P}{P_{0}}=}_{r_{s}-g}^{D_{1}} \\
& r_{s}=\frac{D_{1}}{p_{0}}+g \\
& ?_{P_{0}}=\frac{D_{1}}{\left(1+r_{s}\right)^{1}}+\frac{D_{1}}{\left(1+r_{s}\right)^{2}}+\ldots+\frac{D_{\infty}}{\left(1+r_{d}\right)^{\infty}}
\end{aligned}
$$

COVID 19'un ilk etkisi turizm nakit düzeyinin yani turizm gelirlerinin azalması yönünde olacaktır. Gelirlerin azaldığı bir ortamda turizm şirketleri temettü ödemelerini azaltacaklar veya temettü dağıtmaktan vazgeçeceklerdir. Her iki durumda $\mathrm{D}_{1}$ 'in azalarak şapka $\mathrm{P}_{0}$ 'nın düşmesine yol açacaktır. Dolayısıyla nakit düzeyi azalır, kâr azalır ve turizm şirketinin pay senedi fiyatı yani piyasa değeri düşer. İkinci etkisi, turizm şirketlerinin büyümesine yani yatırım kararlarına olacak olan etkisidir. COVID 19'un etkisiyle büyüme azalacak veya yatırımdan vazgeçeceklerdir. Gordon Modeli yaklaşımında (11) numaralı denklemde g değişkeninin azalması kesrin payda kısmını büyüterek şapka $P_{0}$ 'nın bir kez daha düşmesine yol açacaktır. Tüm bunlar turizm şirket ortaklarının veya yatırımcıların beklenen değerinin düşmesiyle sonuçlanacaktır. Bu durum iskonto edilmiş kâr payı yöntemiyle de açılanabilir. 
Turizm şirketlerinin piyasa değerinin düşmesini gösteren ilişkinin matematiksel formu (13) numaralı denklemde gösterilmiştir. Formülde, VF şirketin piyasa değerini, FCF serbest nakit akışını, WACC ağırlıklı ortalama sermaye maliyetini göstermektedir. FCF'nin azaldığı ve borçlanmanın ile özsermaye finansman maliyetinin arttığı başka bir ifadeyele WACC'ın arttı̆̆ bir ortamda turizm şirketlerinin piyasa değerini düşürecektir.

$$
V_{F}=\frac{F C F_{1}}{(1+W A C C)^{1}}+\frac{F C F_{2}}{(1+W A C C)^{2}}+\ldots+\frac{F C F_{\infty}}{(1+W A C C)^{\infty}}
$$

\section{Sonuç}

Çalışmanın temel amacı Türkiye'de 1969-2020 yıllarında Turizm sektörünün gösterdiği performansın WASPAS yöntemiyle analiz edilmesidir. Turizm sektörünün yıllar itibarıyla en iyi performans gösterdiği dönem 2000'li y1llar olarak dikkat çekerken en düşük performans gösteren dönemin 1970'li yılların olduğu görülmektedir. Elde edilen bulgular WASPAS yöntemin etkinlik özelliğini sağlamaktadır. Ceteris Paribus varsayım altında Türkiye'de Turizm Sektörüne etki eden temel faktör döviz kurlarıdır. Döviz kurlarının yükseldiği bir dönemde turizm gelirlerinin artması beklenir.

Diğer yandan, Koronavirüs pandemisinden kaynaklanan turizm sektörüne yönelik bu büyük şok ekonominin tamamını etkilemektedir. Özellikle turizm sektörün birçok iş kolunu ve işletmeyi desteklediği ülkelerde ekonomik etkileri daha büyük olabilmektedir. Sektörün tüm dallarındaki turizm işletmeleri krizin ön saflarında yer almaktadır. $\mathrm{Bu}$ yüzden hükümetler ekonomik etkiyi azaltmak ve turizm ekonomisinin toparlanmasını desteklemek için politika önlemleri almaktadır. Turizm sektörü için ekonomik toparlamanın başlangıç noktası iç turizm yeniden başlamasıdır. İç turizm de sınırlama önlemlerinden büyük ölçüde etkilenmektedir. İç turizm iyileşme aşamasında önemli bir rol oynayarak hızlı bir toparlanma yaratması beklenmektedir. Turizm sektörü birçok ulusal ekonominin önemli bir parçası ve kilit sektörüdür.

\section{Kaynakça}

Assaf, A. G., \& Josiassen, A. (2012). "Identifying and ranking the determinants of tourism performance: A global investigation". Journal of Travel Research, 51(4), 388-399.

Augustyn, M. M., \& Knowles, T. (2000). "Performance of tourism partnerships: a focus on York". Tourism management, 21(4), 341-351.

Barros, C. P., Botti, L., Peypoch, N., Robinot, E., \& Solonandrasana, B. (2011). "Performance of French destinations: Tourism attraction perspectives". Tourism Management, 32(1), 141146.

Boley, B. B., McGehee, N. G., \& Hammett, A. T. (2017). "Importance-performance analysis (IPA) of sustainable tourism initiatives: The resident perspective". Tourism Management, 58, 6677.

Castellani, V., \& Sala, S. (2010). "Sustainable performance index for tourism policy development". Tourism management, 31(6), 871-880.

Chakraborty, S., Zavadskas, E. K., \& Antucheviciene, J. (2015). "Applications of WASPAS method as a multi-criteria decision-making tool". Economic Computation and Economic Cybernetics Studies and Research, 49(1), 5-22. 
Chen, M. H. (2010). "The economy, tourism growth and corporate performance in the Taiwanese hotel industry". Tourism Management, 31(5), 665-675.

Chen, M. H. (2011). "The response of hotel performance to international tourism development and crisis events". International Journal of Hospitality Management, 30(1), 200-212.

Croes, R. R. (2005). "Value as a measure of tourism performance in the era of globalization: conceptual considerations and empirical findings". Tourism Analysis, 9(4), 255-267.

Farzanegan, M. R., Gholipour, H. F., Feizi, M., Nunkoo, R., \& Andargoli, A. E. (2020). "International Tourism and Outbreak of Coronavirus (COVID-19): A Cross-Country Analysis". Journal of Travel Research. 1-6.

Gössling, S., Scott, D., \& Hall, C. M. (2020). "Pandemics, tourism and global change: a rapid assessment of COVID-19". Journal of Sustainable Tourism, 1-20.

Hashemkhani Zolfani, S., Sedaghat, M., Maknoon, R., \& Zavadskas, E. K. (2015). "Sustainable tourism: a comprehensive literature review on frameworks and applications". Economic Research-Ekonomska Istraživanja, 28(1), 1-30.

Higgins-Desbiolles, F. (2020). "Socialising tourism for social and ecological justice after COVID19”. Tourism Geographies, 1-14.

Inoue, Y., \& Lee, S. (2011). "Effects of different dimensions of corporate social responsibility on corporate financial performance in tourism-related industries". Tourism Management, 32(4), 790-804.

Phillips, P., \& Louvieris, P. (2005). "Performance measurement systems in tourism, hospitality, and leisure small medium-sized enterprises: a balanced scorecard perspective". Journal of Travel Research, 44(2), 201-211.

Qiu, R. T., Park, J., Li, S., \& Song, H. (2020). "Social costs of tourism during the COVID-19 pandemic". Annals of Tourism Research, 84, 102994.

Renaud, L. (2020). "Reconsidering global mobility-distancing from mass cruise tourism in the aftermath of COVID-19". Tourism Geographies, 1-11.

Rodríguez Díaz, M., \& Espino Rodríguez, T. F. (2016). "Determining the sustainability factors and performance of a tourism destination from the stakeholders' perspective". Sustainability, 8(9), 951-958.

Theodoulidis, B., Diaz, D., Crotto, F., \& Rancati, E. (2017). "Exploring corporate social responsibility and financial performance through stakeholder theory in the tourism industries". Tourism Management, 62, 173-188.

Y1lmaz, Y., \& Bititci, U. S. (2006). "Performance measurement in tourism: a value chain model". International journal of contemporary hospitality management, 18(4), 341-349.

Zavadskas, E. K., Chakraborty, S., Bhattacharyya, O., \& Antucheviciene, J. (2015). "Application of WASPAS method as an optimization tool in non-traditional machining processes". Information Technology and Control, 44(1), 77-88. 


\section{EKLER}

Ek 1: Karar Matrisi

\begin{tabular}{|c|c|c|c|c|c|c|}
\hline $\begin{array}{c}\text { Kriterlerin } \\
\text { Yönü }\end{array}$ & Max & Max & Max & Min & Min & Min \\
\hline Y1llar & C1 & C2 & C 3 & C4 & C5 & C6 \\
\hline 1969 & 2,7 & 1,6 & 6,8 & 2,9 & 1,6 & 5,3 \\
\hline 1970 & 2,8 & 1,7 & 8,8 & 3,0 & 1,7 & 5,0 \\
\hline 1971 & 2,8 & 1,8 & 9,3 & 3,1 & 1,6 & 3,6 \\
\hline 1972 & 2,9 & 2,0 & 12,4 & 3,2 & 1,8 & 3,8 \\
\hline 1973 & 3,1 & 2,2 & 13 & 3,3 & 2,0 & 4,5 \\
\hline 1974 & 3,2 & 2,3 & 12,6 & 3,6 & 2,2 & 4,0 \\
\hline 1975 & 3,1 & 2,3 & 14,3 & 3,7 & 2,2 & 3,3 \\
\hline 1976 & 3,3 & 2,3 & 9,2 & 3,7 & 2,3 & 4,1 \\
\hline 1977 & 3,2 & 2,3 & 11,7 & 3,8 & 2,4 & 4,6 \\
\hline 1978 & 3,4 & 2,4 & 10,1 & 3,7 & 2,0 & 2,2 \\
\hline 1979 & 3,4 & 2,4 & 12,4 & 3,7 & 2,0 & 1,9 \\
\hline 1980 & 3,5 & 2,5 & 11,2 & 3,9 & 2,1 & 1,5 \\
\hline 1981 & 3,7 & 2,6 & 8,1 & 4,0 & 2,0 & 1,2 \\
\hline 1982 & 3,8 & 2,6 & 6,4 & 3,9 & 2,0 & 1,2 \\
\hline 1983 & 3,8 & 2,6 & 7,2 & 4,0 & 2,1 & 1,4 \\
\hline 1984 & 3,9 & 2,9 & 11,8 & 4,0 & 2,4 & 2,6 \\
\hline 1985 & 3,9 & 3,2 & 18,6 & 4,1 & 2,5 & 2,9 \\
\hline 1986 & 3,9 & 3,1 & 16,3 & 4,0 & 2,5 & 2,8 \\
\hline 1987 & 4,0 & 3,2 & 16,9 & 4,2 & 2,7 & 3,2 \\
\hline 1988 & 4,1 & 3,4 & 20,2 & 4,2 & 2,6 & 2,5 \\
\hline 1989 & 4,1 & 3,4 & 22 & 4,2 & 2,8 & 3,6 \\
\hline 1990 & 4,1 & 3,5 & 24,9 & 4,3 & 2,7 & 2,3 \\
\hline 1991 & 4,1 & 3,4 & 19,5 & 4,3 & 2,8 & 2,8 \\
\hline 1992 & 4,2 & 3,6 & 24,7 & 4,4 & 2,9 & 3,4 \\
\hline 1993 & 4,2 & 3,6 & 25,8 & 4,5 & 3,0 & 3,2 \\
\hline 1994 & 4,3 & 3,6 & 23,9 & 4,4 & 2,9 & 3,7 \\
\hline 1995 & 4,3 & 3,7 & 22,9 & 4,6 & 3,0 & 2,6 \\
\hline 1996 & 4,4 & 3,8 & 25,7 & 4,6 & 3,1 & 2,9 \\
\hline 1997 & 4,4 & 3,9 & 30,8 & 4,7 & 3,2 & 3,5 \\
\hline 1998 & 4,4 & 3,9 & 28,9 & 4,7 & 3,2 & 3,8 \\
\hline 1999 & 4,4 & 3,7 & 19,6 & 4,6 & 3,2 & 3,6 \\
\hline 2000 & 4,4 & 3,9 & 27,5 & 4,7 & 3,2 & 3,1 \\
\hline 2001 & 4,5 & 4,0 & 33,4 & 4,6 & 3,2 & 4,2 \\
\hline 2002 & 4,6 & 4,1 & 34,4 & 4,7 & 3,3 & 3,6 \\
\hline 2003 & 4,7 & 4,1 & 29,3 & 4,8 & 3,4 & 3,5 \\
\hline 2004 & 4,8 & 4,2 & 27 & 5,0 & 3,5 & 3,0 \\
\hline 2005 & 4,9 & 4,3 & 27,7 & 5,1 & 3,5 & 2,9 \\
\hline 2006 & 4,9 & 4,3 & 21,7 & 5,1 & 3,5 & 2,3 \\
\hline 2007 & 5,0 & 4,3 & 19,5 & 5,2 & 3,6 & 2,4 \\
\hline 2008 & 5,1 & 4,4 & 19,2 & 5,3 & 3,6 & 2,1 \\
\hline 2009 & 5,0 & 4,4 & 24,5 & 5,1 & 3,7 & 3,6 \\
\hline 2010 & 5,1 & 4,4 & 21,9 & 5,3 & 3,8 & 3,2 \\
\hline 2011 & 5,1 & 4,4 & 20,8 & 5,4 & 3,7 & 2,3 \\
\hline 2012 & 5,2 & 4,5 & 19,2 & 5,4 & 3,7 & 1,9 \\
\hline 2013 & 5,2 & 4,5 & 21,3 & 5,4 & 3,7 & 2,1 \\
\hline 2014 & 5,2 & 4,5 & 21,8 & 5,4 & 3,7 & 2,2 \\
\hline & & & & & \\
\hline
\end{tabular}

Turkish Studies - Economy, 15(3) 
Türkiye'de 1969-2020 Yılları Turizm Sektör Performansının Waspas Yöntemiyle Analizi...

\begin{tabular}{|c|c|c|c|c|c|c|}
2015 & 5,2 & 4,5 & 21,9 & 5,3 & 3,8 & 2,8 \\
\hline 2016 & 5,2 & 4,5 & 21,9 & 5,3 & 3,8 & 2,8 \\
\hline 2017 & 5,2 & 4,3 & 15,5 & 5,3 & 3,7 & 2,5 \\
\hline 2018 & 5,2 & 4,4 & 16,7 & 5,4 & 3,7 & 2,2 \\
\hline 2019 & 5,2 & 4,5 & 17,5 & 5,3 & 3,7 & 2,2 \\
\hline 2020 & 5,2 & 4,5 & 20,1 & 5,3 & 3,6 & 2,1 \\
\hline Max, Min & $\mathbf{5 , 2}$ & $\mathbf{4 , 5}$ & $\mathbf{3 4 , 4}$ & $\mathbf{2 , 9}$ & $\mathbf{1 , 6}$ & $\mathbf{1 , 2}$ \\
\hline
\end{tabular}

Ek 2: Normalize Karar Matrisi

\begin{tabular}{|c|c|c|c|c|c|c|}
\hline $\begin{array}{c}\text { Kriterlerin } \\
\text { Yönü }\end{array}$ & Max & Max & Max & Min & Min & Min \\
\hline Y1llar & C1 & C2 & C3 & C4 & C5 & C6 \\
\hline 1969 & 0,52 & 0,34 & 0,20 & 1,00 & 1,00 & 4,56 \\
\hline 1970 & 0,53 & 0,38 & 0,25 & 1,03 & 1,03 & 4,35 \\
\hline 1971 & 0,54 & 0,40 & 0,27 & 1,06 & 1,00 & 3,12 \\
\hline 1972 & 0,56 & 0,44 & 0,36 & 1,10 & 1,09 & 3,28 \\
\hline 1973 & 0,60 & 0,49 & 0,38 & 1,14 & 1,21 & 3,86 \\
\hline 1974 & 0,61 & 0,50 & 0,37 & 1,23 & 1,34 & 3,48 \\
\hline 1975 & 0,60 & 0,51 & 0,42 & 1,27 & 1,35 & 2,83 \\
\hline 1976 & 0,63 & 0,50 & 0,27 & 1,28 & 1,43 & 3,51 \\
\hline 1977 & 0,62 & 0,51 & 0,34 & 1,30 & 1,49 & 4,01 \\
\hline 1978 & 0,64 & 0,52 & 0,29 & 1,26 & 1,24 & 1,93 \\
\hline 1979 & 0,64 & 0,54 & 0,36 & 1,28 & 1,22 & 1,62 \\
\hline 1980 & 0,66 & 0,55 & 0,33 & 1,34 & 1,27 & 1,25 \\
\hline 1981 & 0,70 & 0,57 & 0,24 & 1,36 & 1,24 & 1.00 \\
\hline 1982 & 0,72 & 0,57 & 0,19 & 1,36 & 1,25 & 1,07 \\
\hline 1983 & 0,72 & 0,58 & 0,21 & 1,37 & 1,30 & 1,19 \\
\hline 1984 & 0,74 & 0,64 & 0,34 & 1,39 & 1,50 & 2,23 \\
\hline 1985 & 0,75 & 0,70 & 0,54 & 1,40 & 1,54 & 2,47 \\
\hline 1986 & 0,74 & 0,68 & 0,47 & 1,39 & 1,54 & 2,44 \\
\hline 1987 & 0,77 & 0,71 & 0,49 & 1,43 & 1,63 & 2,73 \\
\hline 1988 & 0,78 & 0,74 & 0,59 & 1,43 & 1,57 & 2,16 \\
\hline 1989 & 0,78 & 0,75 & 0,64 & 1,45 & 1,69 & 3,09 \\
\hline 1990 & 0,79 & 0,77 & 0,72 & 1,50 & 1,67 & 2,02 \\
\hline 1991 & 0,79 & 0,75 & 0,57 & 1,49 & 1,71 & 2,43 \\
\hline 1992 & 0,80 & 0,78 & 0,72 & 1,50 & 1,78 & 2,93 \\
\hline 1993 & 0,80 & 0,79 & 0,75 & 1,54 & 1,83 & 2,74 \\
\hline 1994 & 0,81 & 0,80 & 0,69 & 1,50 & 1,81 & 3,22 \\
\hline 1995 & 0,83 & 0,81 & 0,67 & 1,57 & 1,82 & 2,21 \\
\hline 1996 & 0,83 & 0,83 & 0,75 & 1,60 & 1,91 & 2,51 \\
\hline 1997 & 0,84 & 0,86 & 0,89 & 1,61 & 1,99 & 3,06 \\
\hline 1998 & 0,85 & 0,86 & 0,84 & 1,61 & 2.00 & 3,30 \\
\hline 1999 & 0,85 & 0,82 & 0,57 & 1,59 & 1,95 & 3,13 \\
\hline 2000 & 0,85 & 0,86 & 0,8 & 1,63 & 1,99 & 2,71 \\
\hline 2001 & 0,86 & 0,89 & 0,97 & 1,59 & 1,99 & 3,63 \\
\hline 2002 & 0,87 & 0,90 & 1.00 & 1,62 & 2,01 & 3,15 \\
\hline 2003 & 0,89 & 0,91 & 0,85 & 1,67 & 2,08 & 3,02 \\
\hline 2004 & 0,92 & 0,93 & 0,78 & 1,72 & 2,14 & 2,62 \\
\hline 2005 & 0,93 & 0,95 & 0,80 & 1,75 & 2,17 & 2,51 \\
\hline 2006 & 0,94 & 0,94 & 0,63 & 1,77 & 2,16 & 2,03 \\
\hline 2007 & 0,96 & 0,95 & 0,57 & 1,8 & 2,22 & 2,06 \\
\hline
\end{tabular}




\begin{tabular}{|l|l|l|l|l|l|l|}
2008 & 0,98 & 0,97 & 0,56 & 1,83 & 2,23 & 1,83 \\
\hline 2009 & 0,96 & 0,97 & 0,71 & 1,77 & 2,28 & 3,12 \\
\hline 2010 & 0,97 & 0,97 & 0,64 & 1,81 & 2,32 & 2,74 \\
\hline 2011 & 0,98 & 0,98 & 0,61 & 1,85 & 2,30 & 1,99 \\
\hline 2012 & 0,99 & 0,98 & 0,56 & 1,85 & 2,25 & 1,68 \\
\hline 2013 & 0,99 & 1.00 & 0,62 & 1,85 & 2,29 & 1,82 \\
\hline 2014 & 0,99 & 0,99 & 0,63 & 1,86 & 2,30 & 1,90 \\
\hline 2015 & 0,99 & 0,99 & 0,64 & 1,83 & 2,31 & 2,42 \\
\hline 2016 & 0,99 & 0,99 & 0,64 & 1,83 & 2,31 & 2,42 \\
\hline 2017 & 0,98 & 0,96 & 0,45 & 1,82 & 2,28 & 2,16 \\
\hline 2018 & 0,99 & 0,97 & 0,48 & 1,85 & 2,28 & 1,90 \\
\hline 2019 & 1.00 & 0,99 & 0,51 & 1,84 & 2,27 & 1,90 \\
\hline 2020 & 1.00 & 1.00 & 0,58 & 1,83 & 2,24 & 1,82 \\
\hline
\end{tabular}

Ek 3: Ağırlıklı Toplam Modeline (WSM) Dayalı Toplam Görece Önem Değerleri

\begin{tabular}{|c|c|c|c|c|c|c|c|}
\hline $\begin{array}{c}\text { Kriterlerin } \\
\text { Yönü }\end{array}$ & Max & Max & Max & Min & Min & Min & \\
\hline Yıllar & C1 & C2 & C3 & C4 & C5 & C6 & Q1 \\
\hline 1969 & 0,09 & 0,06 & 0,03 & 0,17 & 0,17 & 0,76 & 1,27 \\
\hline 1970 & 0,09 & 0,06 & 0,04 & 0,17 & 0,17 & 0,72 & 1,26 \\
\hline 1971 & 0,09 & 0,07 & 0,04 & 0,18 & 0,17 & 0,52 & 1,06 \\
\hline 1972 & 0,09 & 0,07 & 0,06 & 0,18 & 0,18 & 0,55 & 1,14 \\
\hline 1973 & 0,10 & 0,08 & 0,06 & 0,19 & 0,20 & 0,64 & 1,28 \\
\hline 1974 & 0,10 & 0,08 & 0,06 & 0,21 & 0,22 & 0,58 & 1,25 \\
\hline 1975 & 0,10 & 0,08 & 0,07 & 0,21 & 0,22 & 0,47 & 1,16 \\
\hline 1976 & 0,10 & 0,08 & 0,04 & 0,21 & 0,24 & 0,58 & 1,27 \\
\hline 1977 & 0,10 & 0,08 & 0,06 & 0,22 & 0,25 & 0,67 & 1,38 \\
\hline 1978 & 0,11 & 0,09 & 0,05 & 0,21 & 0,21 & 0,32 & 0,98 \\
\hline 1979 & 0,11 & 0,09 & 0,06 & 0,21 & 0,20 & 0,27 & 0,94 \\
\hline 1980 & 0,11 & 0,09 & 0,05 & 0,22 & 0,21 & 0,21 & 0,90 \\
\hline 1981 & 0,12 & 0,09 & 0,04 & 0,23 & 0,21 & 0,17 & 0,85 \\
\hline 1982 & 0,12 & 0,09 & 0,03 & 0,23 & 0,21 & 0,18 & 0,86 \\
\hline 1983 & 0,12 & 0,10 & 0,03 & 0,23 & 0,22 & 0,20 & 0,89 \\
\hline 1984 & 0,12 & 0,11 & 0,06 & 0,23 & 0,25 & 0,37 & 1,14 \\
\hline 1985 & 0,12 & 0,12 & 0,09 & 0,23 & 0,26 & 0,41 & 1,23 \\
\hline 1986 & 0,12 & 0,11 & 0,08 & 0,23 & 0,26 & 0,41 & 1,21 \\
\hline 1987 & 0,13 & 0,12 & 0,08 & 0,24 & 0,27 & 0,46 & 1,29 \\
\hline 1988 & 0,13 & 0,12 & 0,10 & 0,24 & 0,26 & 0,36 & 1,21 \\
\hline 1989 & 0,13 & 0,13 & 0,11 & 0,24 & 0,28 & 0,52 & 1,40 \\
\hline 1990 & 0,13 & 0,13 & 0,12 & 0,25 & 0,28 & 0,34 & 1,24 \\
\hline 1991 & 0,13 & 0,13 & 0,09 & 0,25 & 0,28 & 0,41 & 1,29 \\
\hline 1992 & 0,13 & 0,13 & 0,12 & 0,25 & 0,30 & 0,49 & 1,42 \\
\hline 1993 & 0,13 & 0,13 & 0,12 & 0,26 & 0,30 & 0,46 & 1,41 \\
\hline 1994 & 0,14 & 0,13 & 0,12 & 0,25 & 0,30 & 0,54 & 1,47 \\
\hline 1995 & 0,14 & 0,14 & 0,11 & 0,26 & 0,30 & 0,37 & 1,32 \\
\hline 1996 & 0,14 & 0,14 & 0,12 & 0,27 & 0,32 & 0,42 & 1,40 \\
\hline 1997 & 0,14 & 0,14 & 0,15 & 0,27 & 0,33 & 0,51 & 1,54 \\
\hline 1998 & 0,14 & 0,14 & 0,14 & 0,27 & 0,33 & 0,55 & 1,57 \\
\hline 1999 & 0,14 & 0,14 & 0,09 & 0,26 & 0,32 & 0,52 & 1,48 \\
\hline 2000 & 0,14 & 0,14 & 0,13 & 0,27 & 0,33 & 0,45 & 1,47 \\
\hline 2001 & 0,14 & 0,15 & 0,16 & 0,26 & 0,33 & 0,60 & 1,65 \\
\hline 2002 & 0,15 & 0,15 & 0,17 & 0,27 & 0,34 & 0,53 & 1,59 \\
\hline 2003 & 0,15 & 0,15 & 0,14 & 0,28 & 0,35 & 0,50 & 1,57 \\
\hline & & & & & & & \\
\hline
\end{tabular}

Turkish Studies - Economy, 15(3) 
Türkiye'de 1969-2020 Yılları Turizm Sektör Performansının Waspas Yöntemiyle Analizi...

\begin{tabular}{|l|l|l|l|l|l|l|l|}
2004 & 0,15 & 0,16 & 0,13 & 0,29 & 0,36 & 0,44 & 1,52 \\
\hline 2005 & 0,15 & 0,16 & 0,13 & 0,29 & 0,36 & 0,42 & 1,52 \\
\hline 2006 & 0,16 & 0,16 & 0,11 & 0,30 & 0,36 & 0,34 & 1,41 \\
\hline 2007 & 0,16 & 0,16 & 0,09 & 0,30 & 0,37 & 0,34 & 1,43 \\
\hline 2008 & 0,16 & 0,16 & 0,09 & 0,30 & 0,37 & 0,30 & 1,40 \\
\hline 2009 & 0,16 & 0,16 & 0,12 & 0,30 & 0,38 & 0,52 & 1,64 \\
\hline 2010 & 0,16 & 0,16 & 0,11 & 0,30 & 0,39 & 0,46 & 1,57 \\
\hline 2011 & 0,16 & 0,16 & 0,10 & 0,31 & 0,38 & 0,33 & 1,45 \\
\hline 2012 & 0,16 & 0,16 & 0,09 & 0,31 & 0,38 & 0,28 & 1,39 \\
\hline 2013 & 0,17 & 0,17 & 0,10 & 0,31 & 0,38 & 0,30 & 1,43 \\
\hline 2014 & 0,16 & 0,17 & 0,11 & 0,31 & 0,38 & 0,32 & 1,45 \\
\hline 2015 & 0,16 & 0,17 & 0,11 & 0,31 & 0,38 & 0,40 & 1,53 \\
\hline 2015 & 0,16 & 0,17 & 0,11 & 0,31 & 0,38 & 0,40 & 1,53 \\
\hline 2016 & 0,16 & 0,16 & 0,07 & 0,30 & 0,38 & 0,36 & 1,44 \\
\hline 2017 & 0,17 & 0,16 & 0,08 & 0,31 & 0,38 & 0,32 & 1,41 \\
\hline 2018 & 0,17 & 0,16 & 0,08 & 0,31 & 0,38 & 0,32 & 1,42 \\
\hline 2019 & 0,17 & 0,17 & 0,10 & 0,30 & 0,37 & 0,30 & 1,41 \\
\hline
\end{tabular}

Ek 4: Ağırlıklı Çarpım Modeline (WPM) Dayalı Toplam Görece Önem Değerleri

\begin{tabular}{|c|c|c|c|c|c|c|c|}
\hline $\begin{array}{c}\text { Kriterlerin } \\
\text { Yönü }\end{array}$ & Max & Max & Max & Min & Min & Min & \\
\hline Yıllar & C1 & C2 & C3 & C4 & C5 & C6 & Q2 \\
\hline 1969 & 0,90 & 0,84 & 0,76 & 1,00 & 1,00 & 1,29 & 0,74 \\
\hline 1970 & 0,90 & 0,85 & 0,80 & 1,00 & 1,01 & 1,28 & 0,79 \\
\hline 1971 & 0,90 & 0,86 & 0,80 & 1,01 & 1,00 & 1,21 & 0,76 \\
\hline 1972 & 0,91 & 0,87 & 0,84 & 1,02 & 1,01 & 1,22 & 0,84 \\
\hline 1973 & 0,92 & 0,89 & 0,85 & 1,02 & 1,03 & 1,25 & 0,92 \\
\hline 1974 & 0,92 & 0,89 & 0,85 & 1,04 & 1,05 & 1,23 & 0,93 \\
\hline 1975 & 0,92 & 0,89 & 0,86 & 1,04 & 1,05 & 1,19 & 0,92 \\
\hline 1976 & 0,93 & 0,89 & 0,80 & 1,04 & 1,06 & 1,23 & 0,90 \\
\hline 1977 & 0,92 & 0,89 & 0,84 & 1,04 & 1,07 & 1,26 & 0,97 \\
\hline 1978 & 0,93 & 0,90 & 0,81 & 1,04 & 1,04 & 1,12 & 0,82 \\
\hline 1979 & 0,93 & 0,90 & 0,84 & 1,04 & 1,03 & 1,08 & 0,82 \\
\hline 1980 & 0,93 & 0,91 & 0,83 & 1,05 & 1,04 & 1,04 & 0,80 \\
\hline 1981 & 0,94 & 0,91 & 0,79 & 1,05 & 1,04 & 1,00 & 0,74 \\
\hline 1982 & 0,95 & 0,91 & 0,76 & 1,05 & 1,04 & 1,01 & 0,72 \\
\hline 1983 & 0,95 & 0,91 & 0,77 & 1,05 & 1,04 & 1,03 & 0,75 \\
\hline 1984 & 0,95 & 0,93 & 0,84 & 1,06 & 1,07 & 1,14 & 0,95 \\
\hline 1985 & 0,95 & 0,94 & 0,90 & 1,06 & 1,08 & 1,16 & 1,07 \\
\hline 1986 & 0,95 & 0,94 & 0,88 & 1,06 & 1,07 & 1,16 & 1,04 \\
\hline 1987 & 0,96 & 0,95 & 0,89 & 1,06 & 1,08 & 1,18 & 1,09 \\
\hline 1988 & 0,96 & 0,95 & 0,91 & 1,06 & 1,08 & 1,14 & 1,09 \\
\hline 1989 & 0,96 & 0,95 & 0,93 & 1,06 & 1,09 & 1,21 & 1,19 \\
\hline 1990 & 0,96 & 0,96 & 0,95 & 1,07 & 1,09 & 1,12 & 1,14 \\
\hline 1991 & 0,96 & 0,95 & 0,91 & 1,07 & 1,09 & 1,16 & 1,13 \\
\hline 1992 & 0,96 & 0,96 & 0,95 & 1,07 & 1,10 & 1,20 & 1,23 \\
\hline 1993 & 0,96 & 0,96 & 0,95 & 1,07 & 1,11 & 1,18 & 1,24 \\
\hline 1994 & 0,97 & 0,96 & 0,94 & 1,07 & 1,10 & 1,21 & 1,26 \\
\hline 1995 & 0,97 & 0,97 & 0,93 & 1,08 & 1,11 & 1,14 & 1,19 \\
\hline 1996 & 0,97 & 0,97 & 0,95 & 1,08 & 1,11 & 1,17 & 1,26 \\
\hline 1997 & 0,97 & 0,98 & 0,98 & 1,08 & 1,12 & 1,20 & 1,36 \\
\hline 1998 & 0,97 & 0,97 & 0,97 & 1,08 & 1,12 & 1,22 & 1,36 \\
\hline 1999 & 0,97 & 0,97 & 0,91 & 1,08 & 1,12 & 1,21 & 1,25 \\
\hline 2000 & 0,97 & 0,97 & 0,96 & 1,08 & 1,12 & 1,18 & 1,31 \\
\hline & & & & & & & \\
\hline
\end{tabular}




\begin{tabular}{|l|l|l|l|l|l|l|l|}
\hline 2001 & 0,97 & 0,98 & 0,99 & 1,08 & 1,12 & 1,24 & 1,43 \\
\hline 2002 & 0,98 & 0,98 & 1,00 & 1,08 & 1,12 & 1,21 & 1,42 \\
\hline 2003 & 0,98 & 0,98 & 0,97 & 1,09 & 1,13 & 1,20 & 1,39 \\
\hline 2004 & 0,99 & 0,99 & 0,96 & 1,09 & 1,13 & 1,17 & 1,36 \\
\hline 2005 & 0,99 & 0,99 & 0,96 & 1,10 & 1,14 & 1,17 & 1,37 \\
\hline 2006 & 0,99 & 0,99 & 0,93 & 1,10 & 1,14 & 1,12 & 1,28 \\
\hline 2007 & 0,99 & 0,99 & 0,91 & 1,10 & 1,14 & 1,13 & 1,27 \\
\hline 2008 & 1,00 & 1,00 & 0,91 & 1,11 & 1,14 & 1,11 & 1,26 \\
\hline 2009 & 0,99 & 0,99 & 0,95 & 1,10 & 1,15 & 1,21 & 1,42 \\
\hline 2010 & 0,99 & 0,99 & 0,93 & 1,10 & 1,15 & 1,18 & 1,38 \\
\hline 2011 & 1,00 & 1,00 & 0,92 & 1,11 & 1,15 & 1,12 & 1,30 \\
\hline 2012 & 1,00 & 1,00 & 0,91 & 1,11 & 1,14 & 1,09 & 1,25 \\
\hline 2013 & 1,00 & 1,00 & 0,92 & 1,11 & 1,15 & 1,10 & 1,30 \\
\hline 2014 & 1,00 & 1,00 & 0,93 & 1,11 & 1,15 & 1,11 & 1,31 \\
\hline 2015 & 1,00 & 1,00 & 0,93 & 1,11 & 1,15 & 1,16 & 1,36 \\
\hline 2015 & 1,00 & 1,00 & 0,93 & 1,11 & 1,15 & 1,16 & 1,36 \\
\hline 2016 & 1,00 & 0,99 & 0,88 & 1,11 & 1,15 & 1,14 & 1,25 \\
\hline 2017 & 1,00 & 1,00 & 0,89 & 1,11 & 1,15 & 1,11 & 1,25 \\
\hline 2018 & 1,00 & 1,00 & 0,89 & 1,11 & 1,15 & 1,11 & 1,26 \\
\hline 2019 & 1,00 & 1,00 & 0,91 & 1,11 & 1,14 & 1,10 & 1,28 \\
\hline
\end{tabular}

Ek 5: Ağırlıklandırılmış Ortak Genel Kriter Değerleri ve Sıralama

\begin{tabular}{|c|c|c|c|}
\hline Yllar & Q1 & Q2 & Q \\
\hline 1969 & 1,2695 & 0,7384 & 1,0040 \\
\hline 1970 & 1,2613 & 0,7853 & 1,0233 \\
\hline 1971 & 1,0629 & 0,7586 & 0,9108 \\
\hline 1972 & 1,1387 & 0,8403 & 0,9895 \\
\hline 1973 & 1,2789 & 0,9164 & 1,0976 \\
\hline 1974 & 1,2543 & 0,9300 & 1,0921 \\
\hline 1975 & 1,1607 & 0,9217 & 1,0412 \\
\hline 1976 & 1,2667 & 0,9008 & 1,0838 \\
\hline 1977 & 1,3769 & 0,9696 & 1,1733 \\
\hline 1978 & 0,9797 & 0,8154 & 0,8976 \\
\hline 1979 & 0,9423 & 0,8245 & 0,8834 \\
\hline 1980 & 0,9006 & 0,7964 & 0,8485 \\
\hline 1981 & 0,8506 & 0,7357 & 0,7931 \\
\hline 1982 & 0,8578 & 0,7189 & 0,7884 \\
\hline 1983 & 0,8922 & 0,7527 & 0,8224 \\
\hline 1984 & 1,1393 & 0,9538 & 1,0466 \\
\hline 1985 & 1,2316 & 1,0696 & 1,1506 \\
\hline 1986 & 1,2102 & 1,0369 & 1,1236 \\
\hline 1987 & 1,2936 & 1,0932 & 1,1934 \\
\hline 1988 & 1,2110 & 1,0864 & 1,1487 \\
\hline 1989 & 1,3993 & 1,1886 & 1,2939 \\
\hline 1990 & 1,2439 & 1,1416 & 1,1928 \\
\hline 1991 & 1,2892 & 1,1303 & 1,2097 \\
\hline 1992 & 1,4182 & 1,2329 & 1,3255 \\
\hline 1993 & 1,4082 & 1,2416 & 1,3249 \\
\hline 1994 & 1,4723 & 1,2572 & 1,3647 \\
\hline 1995 & 1,3170 & 1,1892 & 1,2531 \\
\hline 1996 & 1,4037 & 1,2574 & 1,3306 \\
\hline 1997 & 1,5427 & 1,3618 & 1,4522 \\
\hline 1998 & 1,5742 & 1,3645 & 1,4694 \\
\hline & & & \\
\hline
\end{tabular}


Türkiye'de 1969-2020 Yılları Turizm Sektör Performansının Waspas Yöntemiyle Analizi...

\begin{tabular}{|l|l|l|l|}
1999 & 1,4822 & 1,2494 & 1,3658 \\
\hline 2000 & 1,4724 & 1,3122 & 1,3923 \\
\hline 2001 & 1,6538 & 1,4277 & 1,5408 \\
\hline 2002 & 1,5933 & 1,4169 & 1,5051 \\
\hline 2003 & 1,5712 & 1,3921 & 1,4816 \\
\hline 2004 & 1,5173 & 1,3642 & 1,4408 \\
\hline 2005 & 1,5183 & 1,3747 & 1,4465 \\
\hline 2006 & 1,4120 & 1,2773 & 1,3446 \\
\hline 2007 & 1,4255 & 1,2732 & 1,3494 \\
\hline 2008 & 1,3986 & 1,2575 & 1,3281 \\
\hline 2009 & 1,6354 & 1,4241 & 1,5298 \\
\hline 2010 & 1,5730 & 1,3780 & 1,4755 \\
\hline 2011 & 1,4508 & 1,3044 & 1,3776 \\
\hline 2012 & 1,3856 & 1,2499 & 1,3178 \\
\hline 2013 & 1,4278 & 1,2955 & 1,3616 \\
\hline 2014 & 1,4459 & 1,3104 & 1,3782 \\
\hline 2015 & 1,5286 & 1,3611 & 1,4449 \\
\hline 2016 & 1,5286 & 1,3611 & 1,4449 \\
\hline 2017 & 1,4423 & 1,2498 & 1,3460 \\
\hline 2018 & 1,4138 & 1,2471 & 1,3305 \\
\hline 2019 & 1,4171 & 1,2585 & 1,3378 \\
\hline 2020 & 1,4110 & 1,2772 & 1,3441 \\
\hline
\end{tabular}

Ek 6: En İyi Performans Siralamas1

\begin{tabular}{|c|c|c|}
\hline Yıllar & Q & Siralama \\
\hline 2001 & 1,5408 & 1 \\
\hline 2009 & 1,5298 & 2 \\
\hline 2002 & 1,5051 & 3 \\
\hline 2003 & 1,4816 & 4 \\
\hline 2010 & 1,4755 & 5 \\
\hline 1998 & 1,4694 & 6 \\
\hline 1997 & 1,4522 & 7 \\
\hline 2005 & 1,4465 & 8 \\
\hline 2015 & 1,4449 & 9 \\
\hline 2016 & 1,4449 & 10 \\
\hline 2004 & 1,4408 & 11 \\
\hline 2000 & 1,3923 & 12 \\
\hline 2014 & 1,3782 & 13 \\
\hline 2011 & 1,3776 & 14 \\
\hline 1999 & 1,3658 & 15 \\
\hline 1994 & 1,3647 & 16 \\
\hline 2013 & 1,3616 & 17 \\
\hline 2007 & 1,3494 & 18 \\
\hline 2017 & 1,3460 & 19 \\
\hline 2006 & 1,3446 & 20 \\
\hline 2020 & 1,3441 & 21 \\
\hline 2019 & 1,3378 & 22 \\
\hline 1996 & 1,3306 & 23 \\
\hline 2018 & 1,3305 & 24 \\
\hline 2008 & 1,3281 & 25 \\
\hline 1992 & 1,3255 & 26 \\
\hline 1993 & 1,3249 & 27 \\
\hline 2012 & 1,3178 & 28 \\
\hline
\end{tabular}




\begin{tabular}{|l|l|l|}
\hline 1989 & 1,2939 & 29 \\
\hline 1995 & 1,2531 & 30 \\
\hline 1991 & 1,2097 & 31 \\
\hline 1987 & 1,1934 & 32 \\
\hline 1990 & 1,1928 & 33 \\
\hline 1977 & 1,1733 & 34 \\
\hline 1985 & 1,1506 & 35 \\
\hline 1988 & 1,1487 & 36 \\
\hline 1986 & 1,1236 & 37 \\
\hline 1973 & 1,0976 & 38 \\
\hline 1974 & 1,0921 & 39 \\
\hline 1976 & 1,0838 & 40 \\
\hline 1984 & 1,0466 & 41 \\
\hline 1975 & 1,0412 & 42 \\
\hline 1970 & 1,0233 & 43 \\
\hline 1969 & 1,0040 & 44 \\
\hline 1972 & 0,9895 & 45 \\
\hline 1971 & 0,9108 & 46 \\
\hline 1978 & 0,8976 & 47 \\
\hline 1979 & 0,8834 & 48 \\
\hline 1980 & 0,8485 & 49 \\
\hline 1983 & 0,8224 & 50 \\
\hline 1981 & 0,7931 & 51 \\
\hline 1982 & 0,7884 & 52 \\
\hline & & \\
\hline
\end{tabular}

Ek 7: Optimal Lambda

\begin{tabular}{|c|c|c|}
\hline Yıllar & Q1 & Q2 \\
\hline 1969 & 1,2695 & 0,7384 \\
\hline 1970 & 1,2613 & 0,7853 \\
\hline 1971 & 1,0629 & 0,7586 \\
\hline 1972 & 1,1387 & 0,8403 \\
\hline 1973 & 1,2789 & 0,9164 \\
\hline 1974 & 1,2543 & 0,9300 \\
\hline 1975 & 1,1607 & 0,9217 \\
\hline 1976 & 1,2667 & 0,9008 \\
\hline 1977 & 1,3769 & 0,9696 \\
\hline 1978 & 0,9797 & 0,8154 \\
\hline 1979 & 0,9423 & 0,8245 \\
\hline 1980 & 0,9006 & 0,7964 \\
\hline 1981 & 0,8506 & 0,7357 \\
\hline 1982 & 0,8578 & 0,7189 \\
\hline 1983 & 0,8922 & 0,7527 \\
\hline 1984 & 1,1393 & 0,9538 \\
\hline 1985 & 1,2316 & 1,0696 \\
\hline 1986 & 1,2102 & 1,0369 \\
\hline 1987 & 1,2936 & 1,0932 \\
\hline 1988 & 1,2110 & 1,0864 \\
\hline 1989 & 1,3993 & 1,1886 \\
\hline 1990 & 1,2439 & 1,1416 \\
\hline 1991 & 1,2892 & 1,1303 \\
\hline 1992 & 1,4182 & 1,2329 \\
\hline 1993 & 1,4082 & 1,2416 \\
\hline 1994 & 1,4723 & 1,2572 \\
\hline & & \\
\hline
\end{tabular}

Turkish Studies - Economy, 15(3) 
Türkiye'de 1969-2020 Yılları Turizm Sektör Performansının Waspas Yöntemiyle Analizi... 1161

\begin{tabular}{|c|c|c|}
\hline 1995 & 1,3170 & 1,1892 \\
\hline 1996 & 1,4037 & 1,2574 \\
\hline 1997 & 1,5427 & 1,3618 \\
\hline 1998 & 1,5742 & 1,3645 \\
\hline 1999 & 1,4822 & 1,2494 \\
\hline 2000 & 1,4724 & 1,3122 \\
\hline 2001 & 1,6538 & 1,4277 \\
\hline 2002 & 1,5933 & 1,4169 \\
\hline 2003 & 1,5712 & 1,3921 \\
\hline 2004 & 1,5173 & 1,3642 \\
\hline 2005 & 1,5183 & 1,3747 \\
\hline 2006 & 1,4120 & 1,2773 \\
\hline 2007 & 1,4255 & 1,2732 \\
\hline 2008 & 1,3986 & 1,2575 \\
\hline 2009 & 1,6354 & 1,4241 \\
\hline 2010 & 1,5730 & 1,3780 \\
\hline 2011 & 1,4508 & 1,3044 \\
\hline 2012 & 1,3856 & 1,2499 \\
\hline 2013 & 1,4278 & 1,2955 \\
\hline 2014 & 1,4459 & 1,3104 \\
\hline 2015 & 1,5286 & 1,3611 \\
\hline 2016 & 1,5286 & 1,3611 \\
\hline 2017 & 1,4423 & 1,2498 \\
\hline 2018 & 1,4138 & 1,2471 \\
\hline 2019 & 1,4171 & 1,2585 \\
\hline 2020 & 1,4110 & 1,2772 \\
\hline St.Sapma & 0,2062 & 0,2246 \\
\hline Opt.Lambda & 0,5428 & \multicolumn{1}{|c}{} \\
\hline & \multicolumn{1}{|c}{} &
\end{tabular}

